\title{
A Governance Analysis of the Galápagos Marine Reserve
}

Peter JS Jones, Dept of Geography, University College London (UCL), Gower Street, London, WC1E 6BT, UK, Tel +44 207679 0528, P.J.Jones@ucl.ac.uk

Paper in a special issue of Marine Policy: Governing marine protected areas: towards social-ecological resilience through institutional diversity. Editors - De Santo EM, Jones PJS, Qiu W and Clifton J (based on MPA Governance project www.mpag.info)

This is the author's version of this paper, which is the same as the final published paper. The published version, all rights for which are reserved by Elsevier Ltd, is available at http://dx.doi.org/10.1016/j.marpol.2012.12.019. This copy is available here

\begin{abstract}
The Galápagos Marine Reserve (GMR) has faced major governance challenges since its designation in 1998, largely due to the driving forces of immigration from the mainland; a heterogeneous population that has a mainland rather than an island identity; increasing demand for marine resources from global seafood markets; and the rapid growth of tourism. Until recently, the pressures related to these driving forces had challenged measures to promote the effectiveness of the GMR. Decisions taken through the participatory management structure were often undermined by a combination of civil unrest, illegal activities and lack of enforcement. A recent period of relative political stability, coupled with several new measures to address these driving forces, has improved the potential effectiveness of the governance framework. These measures include controls on immigration, the use of remote surveillance technologies to enforce fishing restrictions and a system for the improved management of tourism vessels. Whilst participative and economic incentives will continue to be important, increasing political will to promote long-term sustainability and related improvements in the use of legal incentives, including enforcement technologies and effective prosecutions for those who breach restrictions, are likely to be key elements of the governance framework. It is argued that these measures, coupled with the emergence of a more marine-aware generation of Galápagos citizens, should pave the way for major improvements in the effectiveness of the GMR, hopefully sufficiently strengthening the governance framework to withstand the major driving forces that could otherwise perturb it.
\end{abstract}

\section{Key words}

Galápagos, marine, conservation, governance, resilience, effectiveness

\section{Research Highlights}

- The Galápagos Marine Reserve has faced governance challenges due to driving forces

- Effectiveness has been undermined and this has reduced ecosystem resilience

- An improved and more diverse range of incentives should improve governance

- Stronger legal incentives are needed to reinforce the governance framework

- Recent initiatives coupled with increasing political will should increase resilience 


\section{CONTEXT}

The Galápagos Islands straddle the equator $1000 \mathrm{~km}$ due east of the coast of continental Ecuador. The islands are globally renowned as the cradle of Charles Darwin's theory of evolution. The Galápagos Marine Reserve (GMR) was created in 1998, spans an area of 138,000 km² (out to 40 nautical miles from the baseline of the islands) and was declared a World Heritage Site in 2001. The GMR lies at the confluence of major ocean currents - the cool Humboldt Current from the south, and the warm Panama Current from the north. Both influence the strength of the eastward-flowing South Equatorial Current and provide substantial seasonality for an equatorial location. From the west, the deep, cold Cromwell Current upwells around the Galápagos platform, bringing nutrient rich water to the surface and resulting in areas of extremely high productivity. Multiple currents bringing species from diverse source areas to the many GMR habitats have given rise to an exceptionally diverse range of marine organisms, which includes cold water penguins and fur seals to warm water corals and hammerhead sharks [1].

Against this background of biological wealth, Ecuador's per capita income is relatively low at US\$7500, but average income on the Galápagos Islands is nearly twice as high. The difference is due mostly to income from tourism, as well as public sector employment, where salaries are mandated to be $75 \%$ higher than on the mainland. Substantial international aid, especially for conservation and sustainable development initiatives, also contributes to higher incomes [2].

With regards to the governance of the islands' natural heritage, Ecuador's capacity and commitment to frame and enforce restrictions is steadily recovering from a long period of political instability and chronic underfunding. The Galápagos National Park (GNP, under auspices of which GMR is managed) Director is appointed directly by the Minister of Environment through a process that takes into account, but is not entirely dependent on, merit-based selection. A succession of 11 directors and interim directors was appointed between 2004 and 2007, something that made long term planning to promote management effectiveness practically impossible [3]. Moreover, the growth of tourism and the related environmental impacts prompted the Ecuadorian Government to declare Galápagos in a state of emergency and to later support UNESCO's decision to place the Islands on the List of World Heritage Sites in Danger in June 2007.

As a result, the Ecuadorian Government prioritized the identification of solutions relating to tourism management, immigration control, invasive species management and long-term development planning. The national government also identified an urgent need for integrated planning and environmental management, especially for the four populated islands, and the need for local institutions, in particular the three municipalities, to improve their attention and capacity to address problems stemming from rapid growth and unplanned development. As a result of this prioritisation, including the related initiatives to improve the effectiveness of the GMR discussed in this paper, Galápagos was withdrawn from the List of World Heritage Sites in Danger in July 2010, despite IUCN's advice that this was premature, in that "threats from tourism, invasive species and overfishing are still factors and the situation in the Galapagos remains critical ${ }^{1 "}$.

The main stakeholders for the GMR are the tourism and local fishing sectors (all fishing in the GMR is restricted only to Galápagos residents and locally registered vessels), the conservation and science sector (both local and international), the Ecuadorian Navy and the Galápagos National Park Service (GNPS), who have the official responsibilities for managing the reserve.

\footnotetext{
1 Tim Badman, Director, World Heritage Committee - IUCN News Release Galapagos off danger list but still at risk (www.iucn.org/?5763/Galapagos-off-danger-list-but-still-at-risk)
}

Jones PJS (2013) A Governance Analysis of the Galápagos Marine Reserve. Marine Policy, 41, 65-71

doi:10.1016/j.marpol.2012.12.019 


\section{GMR MANAGEMENT OBJECTIVES}

The Galápagos Special Law (1998) established the GMR's overarching objective - the protection of the archipelago's marine biodiversity, both in terms of its intrinsic (preservation) and utilitarian (fisheries and tourism) values. The Management Plan states that the main aim of the GMR is to "protect and conserve the coastal-marine ecosystems of the archipelago and their biological diversity for the benefit of humanity, the local population, science and education." [4]. Accordingly, the Management Plan details a series of 12 specific objectives, encompassing the long term conservation of marine and coastal habitats, endemic and vulnerable species, and resource species, including management actions for their recovery where necessary; and social objectives which include to:

- Support local fishers to maintain and improve their social and economic status, by ensuring fishing activities that are compatible with biodiversity conservation

- Conserve marine-coastal ecosystems as the economic basis for controlled tourism, and to prevent and mitigate any impacts caused by tourism

- Promote science aimed at understanding marine biodiversity and areas and sites affected by human activities

The GMR management plan stipulates the need to take into account the precautionary principle and to provide for adaptive management based on a solid scientific basis, stakeholder participation and sustainable use. An updated management planning process for the GNP began in 2012.

\section{DRIVERS and CONFLICTS}

Tourism is the main driver of the Galápagos economy, accounting for $78 \%$ of all employment, compared to less than $5 \%$ in fishing. Tourism is based mainly on a fixed number of live aboard boats with a maximum capacity of 96 passengers. However, the number of hotels to service land-based tourism is growing rapidly. Overall tourist numbers increased by about 150\% between 1992 and 2006 [5]. Tourism is relatively well managed, but it still has some significant impacts, mainly through vessel groundings, fuel spills, population and infrastructure growth, invasive species and accidental pathogen introductions. Additionally, in recent years a shift has occurred from 'nature' tourism to 'adventure' tourism (kayaking, biking) and this has increased some impacts [5].

The main driving forces that are straining the governance structures and underpinning the environmental degradation and local conflicts associated with the GMR include:

Population growth from 6,000 inhabitants in 1982 to around 25,000 in 2012 [6], stimulated by a tourism and fishing boom that have created a 'gold rush' or 'frontier' culture. Although the Ecuadorian government has successfully implemented innovative legislation under the Galápagos Special Law that restricts immigration, the fact that the average income in Galápagos is almost twice as high as mainland Ecuador creates a powerful pull for continued legal and illegal immigration.

Very recent colonization: post 1930 on Santa Cruz, the most populous island; immigration from the high Andes and fertile Ecuadorian coastal plains has resulted in a highly heterogeneous and transient society that has not yet learned to live sustainably within the limitations imposed by a fragile island ecosystem.

'Mainland-ization': strong family and cultural connections to mainland Ecuadorian urban centres, permanent exposure to a constant influx of wealthy tourists and relatively few opportunities for the local populace to pursue recreational opportunities in the strictly protected GNP and GMR, has driven the desire for a more affluent lifestyle, which is often at odds with environmentally responsible consumption [7].

Jones PJS (2013) A Governance Analysis of the Galápagos Marine Reserve. Marine Policy, 41, 65-71 doi:10.1016/j.marpol.2012.12.019 
Strong pressure from globalized markets, especially in Asia, particularly for sea cucumbers and shark fins, has driven pressure from illegal vessels, especially long-liners from mainland Ecuador, but also adjacent countries, especially Costa Rica. Lucrative export fisheries also drive unsustainable fishing by the local fleet, as local fishermen attempt to cash in on open access fisheries, pitting cooperatives against one another to capture more remote and deeper stocks, including during seasonal closures and in de jure no take zones, which further depresses the recovery of depleted stocks.

The rapid growth of tourism and leakage of related benefits: the relatively weak participation of the local community in the most visible and lucrative tourism operations, which results in the perception that insufficient benefits are accrued from supporting biodiversity conservation. This leakage of benefits from the Galápagos economy [5], despite the revenue raised by entry fees, undermines local willingness to comply with environmental regulations that tend to strongly restrict local access to GNP and GMR areas and resources.

The impacts of these driving forces are exacerbated by overlapping, contested or ambiguous jurisdictions and roles, which undermine effective governance. This especially relates to the role of the GNPS with respect to the navy in terms of GMR enforcement, with respect to the local municipalities regarding the management areas where locally based tourism occurs, and concerning the management of Baltra Island, where the Ecuadorian Air Force has some responsibilities and the GNPS has others.

\section{GOVERNANCE FRAMEWORK/APPROACH}

In 1986, the Ecuadorian government designated the marine area surrounding the Galápagos Islands out to 40 nautical miles as a Marine Resource Reserve Area. This designation constituted little more than a 'paper park', with no management plan, and the designation was met with opposition, including from potentially affected users and from politicians concerned about the impacts on their constituents. In 1996 the area was designated a Biological Reserve, which also led to protests. The problems caused by this previous top-down governance approach led to the designation of the GMR in 1998 under the Galápagos Special Law, with the emphasis on a more participatory bottom-up approach [8], through a two-tier governance framework:-

Participatory Management Board (PMB)

At the local level, the Galápagos Special Law created a decision making body comprised of local representatives of the tourism, naturalist guide and fishing sectors, as well as the GNPS and the Charles Darwin Foundation (CDF). In 2008, the science, conservation and education sector became a full voting member of the PMB. The PMB's role is to evaluate and attempt to reach a consensus on management proposals relating to the GMR. The PMB has mostly focused on fishing issues, which has generated opposition from local fishing groups, which claim there is undue attention to issues that directly affect their livelihoods. This, in turn, has undermined the attempt to increase local decision-making as some consider that fishing associations have tended to resort to external support from mainland-based politicians to achieve their aims when they perceive that local processes are failing them. Another weakness of the PMB has been negotiated positions that, on the one hand, do provide for consensus to be reached, but on the other hand, do so at the cost of undermining decisions and sacrificing science-based recommendations to adopt measures aimed at making user activities more sustainable. This, in turn, leads to isolation and local community rejection of PMB voting members that advocate more strongly for science-based decisions.

Inter-Institutional Management Authority (IMA)

This is the executive decision making body of the GMR. It is presided over by Ecuador's Minister of Environment, and composed of three additional ministries: Tourism, Fishing and Defence. Additional seats are occupied by the local fishing sector and the local tourism sector. Both the CDF and GNPS play

Jones PJS (2013) A Governance Analysis of the Galápagos Marine Reserve. Marine Policy, 41, 65-71

doi:10.1016/j.marpol.2012.12.019 
advisory roles on the IMA. All decisions taken by the PMB must be reviewed by the IMA, which is charged with formulating legally binding resolutions. Normally decisions reached on a consensus basis by the PMB are ratified by the IMA, but when consensus is not reached at the PMB level, the IMA can decide by majority vote.

Enforcement at sea is carried out in conjunction with the Ecuadorian Navy, but occasional lack of agreement between the Navy and the GNPS regarding enforcement roles in the GMR has weakened enforcement capacity, often at key times, such as during the sea cucumber harvesting season. Under the best of circumstances, given the vast area of the GMR $\left(138,000 \mathrm{~km}^{2}\right)$, enforcement is a major challenge. In an effort to address this challenge, in 2012 the GNPS and Navy began jointly operating a satellite enabled Vessel Monitoring System (VMS) for all fishing vessels over 20 tons. The VMS significantly increased the detection and detention of illegal industrial fishing vessels, although sanctions from the judicial system have been few. In 2012, an Automatic Identification System (AIS) allowing detection and tracking of vessels less than 20 tons is expected to become operational, but the system's success will depend on fitting the many vessels ( 200) legally registered to fish in the GMR with AIS transponders, which poses major logistical and financial challenges. There will, as is also the case with VMS, be a need to follow AIS detections of infringements with significant sanctions in order to provide an effective legal incentive to comply with fishing restrictions in the GMR.

\section{GOVERNANCE AND MANAGEMENT EFFECTIVENESS}

No comprehensive assessment of status and trends in relation to biodiversity and resource conservation objectives in the GMR has been undertaken, and a 'baseline' biodiversity assessment was not undertaken until 2002[1]. Fishing pressure on apex predators (sharks) and pelagic fish (tuna, billfish) has been reduced since the ban on industrial fishing and legislation specifically protecting sharks throughout the entire GMR. Some illegal fishing still takes place in the GMR, in the form of incoming and national vessels fishing in no take zones, fishing for closed stocks and using banned long-lines for the shark fin trade throughout the reserve [9]. The local fishing sector has repeatedly called for authorization to use small-scale long-lines in the protected waters. These calls have resulted in a series of studies that generally showed unacceptable levels of shark and turtle by-catch [10].

Only $6 \%$ of the GMR is designated solely for conservation, whilst $11 \%$ is designated for tourism, in which extractive activities (fishing) are banned [4]. Many fisheries have essentially crashed (current catch levels at $<10 \%$ of recorded highs), particularly those for groupers, lobsters and sea cucumbers. As these fisheries 'bump along the bottom' and catch-per-unit-effort (CPUE) remains relatively low compared to historical highs, most fishing remains just marginally commercially profitable enough to continue to exploit these stocks. The total value of catches declined from around \$7 million in 2003 to less than \$3 million in 2008, indicating the decrease in landings and CPUE. The sea cucumber fishery, once the most lucrative fishing activity in the GMR, was not opened in 2008, 2009 or 2010 due to the low population densities. The fishery opened again in 2011, but, given the low profitability and low population densities, it did not reopen again in 2012. Average densities have not reached the threshold value of 11 sea cucumbers $/ 100 \mathrm{~m}^{2}$ that would trigger reopening the fisheries and have ranged from 3-9 sea cucumbers $/ 100 \mathrm{~m}^{2}$. Spiny lobster catches have also declined steadily since the creation of the GMR $[11,12]$. These trends suggest that the intention of erring in favour of precautionary limits in management decisions to ensure sustainable use has not been met. The broader ecological impacts of the significant reduction in sea cucumber and lobster populations are unknown, but have been cited as a reason for minimal coral and macroalgae regeneration following drastic reductions during El Niño events [13]. This indicates that the lack of effectiveness in achieving the GMR's objectives is undermining ecosystem resilience to wide-scale impacts related to climate change.

Each year the islands receive a significant number of cargo and small private vessels. Although ballast

Jones PJS (2013) A Governance Analysis of the Galápagos Marine Reserve. Marine Policy, 41, 65-71 doi:10.1016/j.marpol.2012.12.019 
water has not yet been found to pose significant threat to the islands, there is concern about the transportation of marine invasive species from this source, as well as on ship's hulls. In order to minimize risks, the GNPS, with the support of CDF, carry out hull inspections, though this practice has yet to become standard. It must be noted that during the high season the number of private sailing vessels that arrive to the islands overwhelm inspection capacity. At the time of writing, a programme is being developed to establish a biological baseline for non-native marine species, especially around port areas (pers. comm. Stuart Banks, Charles Darwin Foundation).

Despite the clear population declines of the main commercial species, the GMR remains one of the top dive sites in the world for large marine animals. The biomass and taxa these islands sustain are important for the diversity of the entire Eastern Tropical Pacific area. Furthermore, there is evidence that cold-water refugia and no take zones have contributed to the improvement of the health of fish populations as their densities and size have been recorded to be higher inside these areas [14].

A challenge that has affected management effectiveness is the fact that most fishermen and the majority of fishing interests are locally based, whereas a significant portion of the tourism interests are not based in Galápagos. As a result, there is a very strong local pressure on local membership of the PMB to take marine resource management decisions that do not have serious short-term economic implications for the fishing sector, even when scientific arguments demonstrate that such measures are required to achieve sustainable fishing. This challenge undermines management effectiveness, consequently resources have failed to recover, hence the assignation of a low management effectiveness score of 1 (some impacts beginning to be addressed) [15]. On the other hand, once the GNPS has evidence of the need for stricter tourism management measures through the use of the newly implemented Tourism Management System (SIMAVIS is the Spanish acronym), there should be much less local pressure to challenge such measures. This dynamic has resulted in relatively high management effectiveness in dealing with the environmental impacts of tourism, but not of fishing.

\section{INCENTIVES}

The incentives that have been used to promote effective governance and those that could be argued to be needed to improve governance are listed in table 1, and some examples are discussed further in this section. 
Table 1 Incentives identified as used and needed in the governance of the Galápagos Marine Reserve [15]

\begin{tabular}{|c|c|c|}
\hline $\begin{array}{l}\text { Incentive } \\
\text { type }\end{array}$ & $\begin{array}{l}\text { Incentives applied to address conflicts and } \\
\text { provide governance steer }\end{array}$ & Incentives needed to improve MPA governance \\
\hline Economic & $\begin{array}{l}\text { - Measures to reduce the 'leakage' of the } \\
\text { economic benefits of the MPA away from } \\
\text { local people, including measures to promote } \\
\text { the fair distribution of such benefits amongst } \\
\text { local people } \\
\text { - Promoting alternative livelihoods and adding } \\
\text { value to seafood products } \\
\text { - Funding from private or NGO sources to } \\
\text { promote the effectiveness of the MPA }\end{array}$ & $\begin{array}{l}\text { - Allocation or reinforcement of } \\
\text { community/user property rights }\end{array}$ \\
\hline Interpretative & $\begin{array}{l}\text { Public communication, education and } \\
\text { awareness-raising on the } \\
\text { importance/vulnerability of marine } \\
\text { ecosystems and the benefits of the MPA }\end{array}$ & \\
\hline Knowledge & $\begin{array}{l}\text { - Integration of local knowledge in MPA } \\
\text { decision-making } \\
\text { - Maximising scientific knowledge to } \\
\text { guide/inform MPA decision-making } \\
\text { Promoting mutual respect and collective } \\
\text { learning between different knowledge owners }\end{array}$ & $\begin{array}{l}\text { Agreed basis for the role of precautionary } \\
\text { approaches in the face of uncertainty }\end{array}$ \\
\hline Legal & $\begin{array}{l}\text { - International-regional-national-local } \\
\text { regulatory obligations that require effective } \\
\text { MPA conservation } \\
\text { - Clarity and consistency in defining legal } \\
\text { objectives of MPAs, general and zone } \\
\text { restrictions, jurisdictional boundaries, roles } \\
\text { and responsibilities of different authorities } \\
\text { and organizations } \\
\text { - Legal provisions to ensure public rights and } \\
\text { transparency in MPA management processes } \\
\text { - Ensuring that sufficient State capacity, } \\
\text { political will, surveillance technologies and } \\
\text { financial resources are available to enforce all } \\
\text { restrictions equitably on all local and } \\
\text { incoming users, including addressing driving } \\
\text { forces }\end{array}$ & $\begin{array}{l}\text { Effective judicial system for penalising } \\
\text { transgressors } \\
\text { - Performance } \\
\text { standards/conditions/criteria/requirements } \\
\text { related to the MPA's conservation objectives } \\
\text { and attached to user/property rights, } \\
\text { participatory governance structures, } \text { etc. } \\
\text { - Increasing state capacity, political will, } \\
\text { surveillance technologies and financial } \\
\text { resources in order to improve enforcement, } \\
\text { including addressing driving forces }\end{array}$ \\
\hline Participative & $\begin{array}{l}\text { Participative governance structures and } \\
\text { processes }\end{array}$ & $\begin{array}{l}\text { - Clarification about the PMB's role under the } \\
\text { new regulatory frameworks. }\end{array}$ \\
\hline
\end{tabular}

\subsection{Economic}

There has been a particular emphasis on the use of economic incentives in the governance of the GMR, through financial support from both the national government and international NGOs. In recent years, the focus has been on maximising internal benefits by minimising the leakage of income from tourism and fishing away from the people of Galápagos. This has also involved promoting the equitable distribution of income amongst different groups, after several studies backed up the hypothesis that nature-based tourism provided relatively few benefits to the local population [5,2]. This approach also aimed to provide stakeholders with incentives to reduce unsustainable practices and play positive, proactive roles in participatory management, as well as to reduce political pressure on the management agencies. The mechanisms to achieve this are many and include utilising property rights allocations, such as limiting the 
number of tourism and fishing operation licenses, locally referred to as 'cupos', owned by individuals or companies. This system relies on ensuring that the legal conditions attached to the cupos, such as not renting tourism licenses to foreign interests, are complied with and effectively enforced, for example, through the withdrawal of property rights from transgressors.

Economic incentives also include the funding provided by the state and NGOs to sustain the facilitation processes of the PMB. This funding has been invested in staffing the PMB, as well as providing for monitoring the PMB's effectiveness and providing financial support to underwrite foregone fishing income associated with fishers taking part in PMB meetings. There have also been activities and funding directed towards strengthening the economy of local users, such as providing support for women's groups interested in processing seafood products and generating income through value-added fishing products. Economic measures have probably contributed to the survival of the participatory management system, but have not yet been adequate to create the sense of ownership and stewardship required to ensure the sustained support for management decisions needed to allow ecosystem protection and recovery.

\subsection{Interpretative}

There is need to scale up efforts to increase awareness of conservation issues, priorities and successes to promote pride in and ownership of the GMR through various media, and to several target audiences. Despite being an island population - and consistent with other 'new' island communities - a significant proportion of the local population does not have a 'marine' identity, as is discussed above in terms of 'mainland-ization'. Thus, important groups of society and decision makers view the MPA as a disconnected issue, not relevant to their interests and welfare, although sporadic outreach campaigns, mostly by the Ecuadorian Navy, have aimed to change this and to introduce children to the marine environment. Such interpretative efforts must continue in the long term to help the local community identify with, understand and appreciate the marine environment, not least as a means of generating support for and cooperation with conservation measures for the GMR.

\subsection{Knowledge}

Knowledge incentives have aimed to improve the socio-economic and ecological knowledge base to support decision-making processes, drawing on both scientific and local knowledge and promoting collective learning. This knowledge base is built on the monitoring programs of management and research institutions, as well as on participatory monitoring surveys. Despite important improvements in data collection and management, deficiencies persist that undermine good governance and management. Fisheries databases require upgrading and are not integrated, and metadata is mostly unavailable. The tourism administration system (SIMAVIS) is a notable exception to this rule. A new wave of knowledge incentives should focus on implementing knowledge management strategies and data transparency. Such measures are likely to increase the legitimacy and stakeholder acceptance of management decisions with a solid and explicit knowledge base.

Knowledge incentives have also tried to establish rules and procedures for implementing and operationalizing the precautionary principle, recognising that there will always be a degree of uncertainty, the use of which to delay or reject decisions should be minimised. Ecuadorian legislation recognises the role of the precautionary principle, but in general the system as a whole lacks mechanisms to help MPA managers back up decisions based on the principle.

\subsection{Legal}

Legal incentives should focus on ensuring that special interests promoted by a vocal minority cannot block difficult decisions taken in the long-term interests of the majority, or ignore such decisions or apply pressure to have them revised through threats of direct action. Also, if management institutions are to sponsor wider schemes of property rights as a means to improve resource stewardship, these access and use privileges must be accompanied by legally enforceable performance conditions regarding meeting 
explicitly agreed sustainability targets for tourism and fishing resources. Failure to meet these targets should lead to the forfeiture of the property rights.

As it stands, the legal framework and enforcement technology in place have proven highly effective in reducing illegal fishing by large-scale, commercial vessels in the GMR. However, there is still need for improvements regarding the management of local vessels in the reserve to ensure respect for both seasonal resource closures and spatial closures, including permanent no take zones. As noted, full implementation of an automatic identification system (AIS) should assist in this task, but will do so only if a comprehensive legal framework is in place that ensures all users deploy and properly maintain transponders on their vessels and that failure to do so is penalised, and that infringements detected through these technologies lead to penalties that provide a a sufficient deterrent. The strengthening of legal incentives should make a key contribution to improving effectiveness through reinforcing the governance framework.

\subsection{Participative}

As the participatory management system aims for the representation of all key stakeholders, a valuable step to making the PMB more inclusive would be to include local users who make extensive recreational use of the GMR. There is also a need for 'tempered' facilitation [16] that steers deliberations in a constructive manner, which is more likely to provide the deliberative, science-based forum required to achieve conservation objectives. Transparency and accountability are particularly important in this respect. Concern exists that some management decisions taken by the PMB have been overzealous in trying to satisfy all parties at the cost of undermining policies required to achieve conservation objectives. If the PMB is to reach its potential, an analysis is urgently needed regarding the degree to which decisions have been data driven, rather than driven by the imperative to achieve a consensus. At the time of this publication, the Ecuadorian government is implementing new regulations that are likely to redesign the participatory mechanisms in the GMR in terms of structure, composition and decision-making ability. These developments will provide the opportunity to improve the decision-making system.

\section{KEY ISSUES}

The governance of the GMR has undergone rapid evolution since the Reserve's creation by the Galápagos Special Law in 1998, which was the first significant milestone in promoting the participation of the local community in defining its future. Creation of the PMB was the second key milestone, but the first five years were fraught with social unrest and conflicts and resource management failure as PMB members consistently failed to negotiate and build consensus around scientific evidence to protect the GMR. The second five-year period has been characterized by the opposite trend: consensus is often reached, but the adoption of difficult decisions has been sporadic. The challenge now is to create incentives so that the next step in the system's evolution is for stakeholders to consistently negotiate around a shared set of long-term objectives and share the burden generated when reaching decisions that create disproportionate short-term costs for any particular stakeholder group.

Major civil unrest and protests in the form of road blockades, takeover of administrative buildings, forced seizure of monitoring vessels, kidnapping of wardens, threats to release invasive goats on cleared islands, etc., were a frequent occurrence between 1995 and 2006. These episodes were generally related to fisheries issues, particularly restrictions on sea cucumber harvesting and prohibitions on long lining, but also reflected the political instability that enveloped Ecuador at that time. Although with much less visible means to achieve their ends, the tourism industry successfully lobbied the government to avoid measures that could limit the number of tourists entering the archipelago, despite data showing a trend that developments have been more and more contradictory with nature-based tourism. In summary, despite the participatory system in place, it is obvious that short-term interests of certain sectors have persistently driven decision-making at the cost of conservation objectives [12].

Jones PJS (2013) A Governance Analysis of the Galápagos Marine Reserve. Marine Policy, 41, 65-71 doi:10.1016/j.marpol.2012.12.019 
The GMR is governed through an approach that provides for the participation of users through representatives of the fishing and tourism industries, along with other environmental representatives. The key problem, however, is that the user representatives on the PMB are lobbied not only by their constituents (domestic fishermen and tourism operators) but also by external forces (international fish markets and tourism operators). This, coupled with the understandable priority of many local people to increase their economic well-being, has led to a participatory governance system that routinely blocks proposals to restrict economic development activities - reduced minimum landing sizes/quotas, reducing numbers of tourist/fishing vessels, etc. [17]. Consensus on such proposals is rarely reached by the PMB and environmental representatives now routinely pass such proposals to the IMA.

This higher-level decision-making platform is, however, subject to the same influences from users and related external forces. Even where such proposals are agreed through the role of the IMA, protests and direct actions have historically led to them subsequently being withdrawn or users ignoring them, enforcement capacity being limited and the process for prosecuting transgressors under civil law being slow and weak [12]. This being said, since 2005 the strikes, including violence and the destruction of property, that had become a regular occurrence in Galápagos, have not occurred. One explanation for the relative calm since the period of tumult has been the consistent adoption of management decisions by the PMB that do not adequately address marine resource conservation needs. A notable exception is the full closure of the sea cucumber fishery since 2000, which may have been considered uncontroversial because the harvests had dwindled, due to previous overexploitation, to the point that sea cucumber merchants may have turned to other sources in other countries, though demand could very easily increase once stocks recover

Economic incentives for supporting PMB facilitation, the development of alternative livelihoods, adding-value to seafood products, etc., have not been sufficient to transform the local community into the natural resource stewards required for the long-term persistence and recovery of marine resources, and in some cases may have created situations of dependency on NGO funding. The potential for green marketing of tourism and fish products to premium, highly responsible ecotourism and certified fish product markets is declining as the conservation status of fish populations and wider biodiversity declines. On the other hand, market demand for a 'watered down' or 'green-washed' version of nature tourism or for fisheries products, even if they come at the cost of the environment itself, seems to be so large as to be a driving force of depletions.

Regarding the knowledge base, scientific evidence that fish populations and wider marine biodiversity is already in a state of serious decline has a relatively high degree of certainty. However, the scientific case for restrictions is still routinely rejected or ignored by users in their efforts to resist such restrictions. One of the key arguments against the case that depletions are caused by overfishing and the indirect impacts of tourism is that natural oceanic variations, such as El Niño events, perhaps exacerbated by wide-scale climate change, are the cause of depletions. Whilst increasing the knowledge base to support stricter management measures will improve the potential for effective governance, short-term vested interests are likely to continue to challenge, reject and ignore such evidence, despite the recognition of the precautionary principle in the GMR Management Plan. This is consistent with the general trend by which precaution is very rarely translated from a principle into decisions that actually affect practice [18]. It is important that challenges to the scientific basis of proposed restrictions from certain vested interest are considered in the light of the precautionary principle, basic rules on the operationalization of which should be formally agreed under the GMR Management Plan. However, the GMR is not alone in this respect, as the operationalization of the precautionary principle is a recurring and major challenge in environmental decision-making.

Between 2009 and 2012, a number of challenging top-down decisions were taken by the Ecuadorian

Jones PJS (2013) A Governance Analysis of the Galápagos Marine Reserve. Marine Policy, 41, 65-71

doi:10.1016/j.marpol.2012.12.019 
government with respect to the management of mainland Ecuador's fishery resources. Many of these decisions were difficult and not always popular, but were based on scientific information and were clearly focused on improving the state of national fisheries. This political context bodes well for the management of the GMR, which requires this sort of high-level political commitment to put local fisheries back on the path of recovery and manage the growth of tourism in a way that maintains it as a sustainable source of low impact economic prosperity for the long-term. However, a significant challenge is posed by the fact that difficult political decisions that produce the perception of short-term economic losses in Galápagos have direct political implications at a national level. As an Ecuadorian province, the people of Galápagos are represented by the minimum number of two National Assembly congressmen. With an electorate of only a little over 10,000 voters, a few thousand Galápagos voters unhappy with a political decision, including those related to the GMR, can replace an incumbent congressman with someone new, thus significantly affecting the national political balance, recognising that the other 122 National Assembly congressmen represent an Ecuadorian population of 15 million people. The consequent potential for proposed GMR restrictions to become politicised at a national level is likely to continue to pose significant challenges, addressing which could be further supported through the continued development of national political will to improve the effectiveness of the GMR, as part of the increased national commitment to sustainability.

Tourism remains subject to strong internal and external pressures for growth, and the locally-based fishing capacity reduces the potential for recovery in fish populations and wider biodiversity. If the same political will that addressed the pressures to deal with local population growth through establishing contentious immigration reforms and in dealing with illegal industrial fishing by incoming vessels could be generated and applied to address the pressures from tourism and unsustainable local fishing, restoration of the conservation status of the GMR is feasible. The difference is that addressing pressures from new immigrants and non-local incoming vessels has clear positive benefits for the local Galápagos community, as these measures served to protect their interests from external competition for economic opportunities and access to marine resources. Initiatives to address the pressures from tourism and local fishing, by contrast, would negatively affect local Galápagos people themselves, at least in the short term, rather than affecting outsiders. When management actions do address local pressures it is important that national and international organisations committed to supporting long-term sustainable solutions provide visible support to the institutions responsible for them.

The GNPS has the legal powers to make some management decisions without the achievement of consensus at the PMB. Careful use of this prerogative, especially in situations where scientific information clearly supports difficult decisions, strengthens the legitimacy and credibility of the GNPS. If a minority of users block proposed management measures through actual or threatened direct action or ignores measures, other users will have no incentive to comply, as benefits that accrue through the recovery of fish populations and marine ecosystems will be undermined or taken advantage of by free riders.

A great deal of effort has been focused on a combination of strengthening the participatory management system and on focusing international attention and raising awareness of the Galápagos population on important marine issues. The GMR's governance approach has been evaluated and was found to be performing well in some respects (strategic vision, participation, empowerment, consensus orientation and resilience) but less well in others (responsible representation, equity and credibility). Some recent authors have noted that the GMR is not performing well in terms of its effectiveness in providing for the fulfilment of fisheries and biodiversity conservation objectives [12].

Against the background of these mixed reviews, it is suggested that the focus of incentives should be to revise the participatory governance approach, recognising that consensus may not be attainable for some proposals, as well as to strengthen the enforcement of legal incentives, backed by strong political will to

Jones PJS (2013) A Governance Analysis of the Galápagos Marine Reserve. Marine Policy, 41, 65-71 doi:10.1016/j.marpol.2012.12.019 
take and enforce decisions, even in the face of challenges by certain vested interests to the scientific basis of such decisions. Such measures are necessary in order to avoid undesirable and potentially irreversible shifts in both the environmental and social systems of the GMR [19]. Of central importance is the need to set clear expectations regarding the costs and benefits of management decisions, as well as paying careful attention to monitoring the accrual of long-term benefits and clearly communicating these to local, national and international stakeholders in order to build confidence and credibility in the management institutions and governance system.

It is important to note, however, that whilst one of the key enabling conditions identified by common-pool resource (CPR) governance researchers is that the state should shift from controller to facilitator [16], in the case of the GMR this is not realistic, as the state must exercise some degree of control in order to (a) prevent local and incoming users (fishers and tourism operators) from undermining collective agreements; and (b) to ensure that wider-scale, longer-term strategic biodiversity conservation and restoration objectives are achieved. The conclusion that both participative and legal incentives should be promoted and strengthened may appear to be a contradiction from a CPR perspective. However, the emphasis must be on combining the strength of all five categories of incentives (economic, interpretative, knowledge, legal and participative) rather than focusing just on particular categories of incentives, as has arguably been the case. Employing a diversity of incentives in the governance framework for the GMR, legal incentives providing vital reinforcement against the potentially perturbing effect of driving forces, should lead to an increased effectiveness in achieving biodiversity conservation objectives, thereby increasing the resilience of both the governance framework and the ecosystems it aims to protect [20].

Finally, a key component for the GMR's governance has to do with the users' cultural values. Despite being an oceanic archipelago, rapid immigration into the Galápagos has resulted in a significant proportion of the local community being disengaged from the marine environment, previously discussed in terms of 'mainland-ization'. However, demographic trends are changing within the islands, in that proportionally more people are now being born and raised in the archipelago than was the case over the past decade, when immigration was largely uncontrolled. Marine-related sports and recreational activities are becoming common in contrast to past years when only fishers and tourism cruises would venture into the GMR. As this group of young marine-aware citizens comes of age to participate in local decision-making, they are anticipated to become a more active and informed constituency that contributes to the sound governance of the GMR. This will be more likely if efforts currently underway are successful in promoting a local culture that highlights the uniqueness of the GMR, its species and the role of the inhabitants as stewards of such a fragile natural heritage.

This governance analysis indicates that whilst the governance framework for the GMR may have had a relatively low management effectiveness in the past, this has by no means been due to a lack of efforts and resources to support the GMR in what are clearly very challenging circumstances. These efforts are continuing through the recent and planned introduction of several measures that should significantly improve the effectiveness of the GMR, particularly controls on immigration, the use of VMS and AIS to better enforce fishing restrictions, a system for the improved management of tourism vessels and the revision of participative decision-making mechanisms. These measures, coupled with the emergence of a new marine-aware generation of Galápagos citizens and increasing political will to take and enforce decisions that promote long-term sustainability, should pave the way for major improvements in the effectiveness of the GMR, hopefully sufficiently strengthening the governance framework to withstand the major driving forces that could perturb it. This represents an evolutionary step that Charles Darwin would almost certainly approve of.

\section{Acknowledgements}

The author is very grateful to Veronica Toral, Alex Hearn, Scott Henderson and Gonzalo Banda-Cruz for their advice, information and inputs, though the views expressed in this paper are solely those of the

Jones PJS (2013) A Governance Analysis of the Galápagos Marine Reserve. Marine Policy, 41, 65-71

doi:10.1016/j.marpol.2012.12.019 
author.

\section{References}

[1] Danulat E, Edgar GJ (eds). Galápagos Marine Reserve: biological baseline. Santa Cruz, Galápagos: Charles Darwin Foundation/ Galápagos National Park Service; 2002.

[2] Taylor JE, Hardner JM, Stewart M. Ecotourism and Economic Growth in the Galápagos: an island-wide analysis. Working Paper No. 06-001; Dept of Agricultural and Resource Economics, University of California Davis; 2006.

[3] Watkins G, Cruz F. Galápagos at Risk: a socioeconomic analysis of the situation in the archipelago. Puerto Ayora, Galápagos: Charles Darwin Foundation; 2007.

[4] GNPS (Galápagos National Park Service). Management Plan for Conservation and Sustainable Use of the Galápagos Marine Reserve; 1998.

[5] Epler B. Tourism, the economy, population growth, and conservation in Galápagos. Puerto Ayora, Galápagos: Charles Darwin Foundation; 2007.

[6] INEC. Resultados del Censo de Población. 2012. http://inec.gob.ec/cpv/ . Accessed 30 ${ }^{\text {th }}$ September 2012.

[7] Grenier C. Conservación Contra Natura. Quito: Abya Yala; 2007.

[8] Heylings P, Bensted-Smith R, Altamirano M. Zonificación e historia de la Reserva Marina de Galápagos. In: Danulat E, Edgar GJ [1]: 10-21; 2002.

[9] Reyes H, Murillo JC. Esfuerzos de control de pesca ilícita en la Reserva Marina. Informe Galápagos 2006-2007. FCD-SPNG-INGALA; 2007

[10] Murillo JC, Banks S, Reyes H, Danulat E, Zarate P. Evaluación de la captura incidental durante el Plan Piloto de Pesca de Altura con Palangre en la Reserva Marina de Galápagos. Galápagos National Park Service; 2004.

[11] Hearn A, Murillo JC, Nicolaides F, Moreno J, Reyes H. Evaluación de la pesquería de langosta espinosa (Panulirus penicillatus y P. gracilis) en la Reserva Marina de Galápagos, 2005. In: Hearn A (Ed) Evaluación de las pesquerías en la Reserva Marina de Galápagos, Informe Compendio 2005. Quito, Ecuador: Charles Darwin Foundation; 2006: 46-116.

[12] Castrejón M, Charles A. Improving fisheries co-management through ecosystem-based spatial management: the Galápagos Marine Reserve. Marine Policy 2012; 38: 235-245

[13] Edgar GJ, Banks SA, Brandt M, Bustamante R, Chiriboga A, Earle SA, Garske LE, Glynn PW, Grove JS, Henderson S, Hickman CP, Miller KA, Rivera F, Wellington G. El Niño, grazers and fisheries interact to greatly elevate extinction risk for Galápagos marine species. Global Change Biology 2010; 16: 2986-2980.

[14] Banks S. Estado de especies y habitáts marinos en Galápagos. In: Cárdenas S, Marín A (Eds) Informe Galápagos 2006-2007. Quito, Ecuador: Fundación Charles Darwin, Parque Nacional Galápagos e Instituto Nacional Galápagos; 2007: 122-127.

[15] Jones PJS, Qiu W, De Santo EM. Governing Marine Protected Areas: getting the balance right. Nairobi: United Nations Environment Programme; 2011. www.mpag.info

[16] Jones PJS, Burgess J. Building partnership capacity for the collaborative management of marine protected areas in the UK: a preliminary analysis. Journal of Environmental Management 2005; 77(3): 227-243

[17] Hearn A. The rocky path to sustainable fisheries and conservation in the Galapágos Marine Reserve. Ocean \& Coastal Management 2008; 51: 567-574

[18] Appleby T, Jones PJS. The marine and coastal access act - A hornets' nest? Marine Policy 2012; 36(1): 73-77.

[19] González, J. A., C. Montes, J. Rodríguez, and W. Tapia. 2008. Rethinking the Galápagos Islands as a complex social-ecological system: implications for conservation and management. Ecology and Society 13(2): 13. [online] URL: http://www.ecologyandsociety.org/vol13/iss2/art13/

[20] Jones PJS, Qiu W, De Santo EM. Governing marine protected areas: social-ecological resilience through institutional diversity. Marine Policy 2013; 41, 5-13

Jones PJS (2013) A Governance Analysis of the Galápagos Marine Reserve. Marine Policy, 41, 65-71 doi:10.1016/j.marpol.2012.12.019 